\title{
Effect of Tempol, a Membrane-Permeable Free Radical Scavenger, on In Vitro Model of Eye Inflammation on Rabbit Corneal Cells
}

\author{
Rosalia Crupi, ${ }^{1, *}$ Daniela Impellizzeri, ${ }^{1,{ }^{*}}$ Enrico Gugliandolo, ${ }^{1}$ Marika Cordaro, ${ }^{1}$ Rosalba Siracusa, \\ Domenico Britti, ${ }^{2}$ Salvatore Cuzzocrea, ${ }^{1,3}$ and Rosanna Di Paola ${ }^{1}$
}

\begin{abstract}
Purpose: Inflammatory corneal diseases such as bacterial keratitis provoke severe injury to the visual functions and physical structure, leading to opaqueness, wounding, damage to the cornea, and even long-lasting vision loss. Usually antioxidant substances have been of great attention as candidate therapies in the management of keratitis in both humans and animals. Based on the findings, the aim of our research was to examine the effects of Tempol (4-hydroxy-2,2,6,6-tetramethylpiperidine-1-oxyl), a membrane-permeable free radical scavenger with exclusive antioxidant properties, on in vitro model of eye inflammation of rabbit corneal cells stimulated with lipopolysaccharide (LPS) (Seruminstitute Rabbit Cornea).

Methods: The cells were pretreated with Tempol and incubated with LPS for $24 \mathrm{~h}$. LPS stimulation triggered increased cellular mortality, oxidative stress, cytokine levels expression of tumor necrosis factor (TNF)- $\alpha$, interleukin (IL)-1 $\beta$ and IL-6, and also enhanced prostaglandin $\mathrm{E}_{2}\left(\mathrm{PGE}_{2}\right)$ levels and cyclooxygenase-2 (COX-2) expression.

Results: Pretreatment with Tempol ( $3 \mathrm{mM})$ significantly increased cell viability and antioxidant activity as well as decreased reactive oxygen species production, cytokines, $\mathrm{PGE}_{2}$ levels, and COX-2 expression.

Conclusions: Taken together, Tempol could be a new therapeutic strategy for management of ocular inflammatory disorders for clinical and veterinary use.
\end{abstract}

Keywords: inflammation, oxidative stress, rabbit corneal, Tempol, keratitis

\section{Introduction}

T NFLAMMATORY CORNEAL DISEASES provoke severe injury to the visual functions and physical structure, leading to opaqueness, wounding, damage to the cornea, and also longlasting loss of vision.

Viruses and bacteria represent the most communal infective agents that distress the ocular surface and cause inflammatory damage. When subjected to the insults, the corneal immune response is activated, with the liberation of cytokines and inflammatory cells infiltration. ${ }^{1}$ Bacterial keratitis is an important ocular infection and one of the key causes of visual disability in the world. ${ }^{2}$

Animals other than humans are possible victims of bacterial keratitis. For example, infective bovine keratoconjunctivitis, normally instigated by Moraxella bovis, is the main healthiness difficulty in cattle. Pseudomonas also caused keratitis in dogs and horses. Cats could also develop bacterial keratitis, but less than dogs. Several other mammals can acquire keratitis, underlining the incidence of bacteria capable to produce eye pathogenesis. ${ }^{3}$

During keratitis, stimulated inflammatory cells release inflammatory cytokines, such as interleukin-6 (IL-6), IL1 beta (IL-1 $\beta$ ), and tumor necrosis factor-alpha (TNF- $\alpha$ ), which then provoke the necrosis of keratocytes and degradation of collagen in stroma. This could result in the reduction of corneal stroma and successive scarring creation. ${ }^{4}$ Several studies reported that corneal injury during inflammatory condition is connected principally to the polymorphonuclear neutrophil (PMN) infiltration in the corneal tissue with the relief of proteolytic enzymes, arachidonic acid, and reactive oxygen species (ROS). ${ }^{5,6}$

\footnotetext{
${ }^{1}$ Department of Chemical, Biological, Pharmaceutical and Environmental Science, University of Messina, Messina, Italy.

${ }^{2}$ Department of Health Sciences, University of Catanzaro "Magna Graecia," Catanzaro, Italy.

${ }^{3}$ Department of Pharmacological and Physiological Science, Saint Louis University School of Medicine, Saint Louis, Missouri.

*These authors contributed equally to this work.
} 
In keratitis, inflammation frequently persists and lapses long after the bacteria were removed, causing numerous injuries to the structure and cornea function. While bacteria and virus could be limited by antibiotics, the immune system, when stimulated, has to be controlled due to pathogen products, for example, lipopolysaccharide (LPS). ${ }^{1}$ Antioxidant treatment may reduce the inflammatory damage and could have a conspicuous function in the therapy of corneal inflammation. The combination with voriconazole and antioxidant epigallocatechin gallate reduces fungal keratitis in rabbits. ${ }^{7}$ Bucolo et al. ${ }^{8}$ demonstrated that taurine (TAU), small organic molecules, significantly reduced ROS production in corneal [Seruminstitute Rabbit Cornea (SIRC)] cells after oxidative stress.

Furthermore, several experimental results showed that both pirenoxine and melatonin prevent the formation of superoxide and oxidative effect in cell culture and entire rabbit corneas submitted to exposure of UV-B. ${ }^{9}$ Taken together, the antioxidant substances have been of pronounced interest as potential therapies for the treatment of keratitis in both humans and animals. In this regard, Tempol (4-hydroxy-2,2,6,6tetramethylpiperidine- $N$-oxyl), a member of a family of nitroxide compounds, has been considerably studied in numerous animal models such as renal ischemia/reperfusion, inflammation induced by zymosan injection, brain injury, and colitis. ${ }^{10-14}$ In addition, regarding ocular pathologies, Tempol protects against cataract, retinal damage, and glaucoma. ${ }^{15-17}$

Based on the data obtained from the scientific literature, the goal of our study was to study the effects of Tempol, a membrane-permeable free radical scavenger with unique antioxidant properties, ${ }^{18,19}$ on in vitro model of eye inflammation of rabbit corneal SIRC line cells, which exhibits several qualities of corneal keratocytes ${ }^{20,21}$ stimulated with LPS (a surrogate for bacterial infection).

\section{Methods}

\section{Cell culture and experimental design}

SIRC is the used cell line (ATCC_CCL-60) with fibroblast morphology. Based on ATCC history, the SIRC cell line was originated by M. Volkert of the Statens Seruminstitut, Copenhagen, Denmark, from the cornea of a normal rabbit in 1957. Little is documented concerning the history of this cell line for about the first 400 passages. This cell line is aneuploid, with a modal number of 66 chromosomes. A previous paper described for the first time the expression of a mix of epithelial and fibroblastic markers in SIRC cells, suggesting a hybrid description of this cell line. In fact, these cells present both epithelial (occludin) and fibroblastic (lumican, $\alpha$-SMA, and vimentin) markers. ${ }^{22}$ In addition, among the cytokeratins, SIRC cells express CK3 and CK12 corneaspecific markers of epithelium. ${ }^{23}$ Eagle's minimum essential medium mixed with $10 \%$ fetal bovine serum was used for cell culture, in which the cells were cultured at $37^{\circ} \mathrm{C}$ and $5 \% \mathrm{CO}_{2}$. Subsequently, they were also placed in 6 -well plates $24 \mathrm{~h}$ before the experimentation at $1.2 \times 10^{5}$ cells/well density in $2 \mathrm{~mL}$ (medium). This was changed daily, and the cells were preserved until subconfluence. The cell line was used within the space of 5 passages in vitro, starting from fresh frozen batches, to avoid phenotypic drift events.

The SIRCs were treated at different concentrations $(1,3$, 6 , and $10 \mathrm{mM}$ ) of Tempol (dissolved in $1 \%$ of DMSO) to ascertain the high dilutions with less toxicity on cell viability. One percent DMSO was used as control. After that, when we found the high concentration with less toxicity, the cells were preincubated in serum-free medium with $3 \mathrm{mM}$ of Tempol for $1 \mathrm{~h}(3 \mathrm{mM}$ was selected based on the cell viability test) and then excited with LPS (from Escherichia coli $1.0 \mu \mathrm{g} \mathrm{mL}$ ) for $24 \mathrm{~h}$ for all experiments.

\section{Cell viability assay}

Cell viability was calculated as described in a previous study. ${ }^{24}$ The cells were incubated at $37^{\circ} \mathrm{C}$ with $0.2 \mathrm{mg} / \mathrm{mL}$ MTT (3-[4,5-dimethylthiazol-2-yl]-2,5 diphenyl tetrazolium bromide) for $1 \mathrm{~h}$. Cell viability was calculated at $550 \mathrm{~nm}$ optical density (OD550) using a microplate reader. ${ }^{24}$

\section{Western blot analysis}

Western blot analysis was done as previously defined ${ }^{24}$ with specific primary anticyclooxygenase-2 (COX2) (1:500) [Santa Cruz Biotechnology (N-20) Cat\# sc-1746, RRID:AB_627284] and secondary antibody (1:2,000; Jackson ImmunoResearch, West Grove, PA). The $\beta$-actin (1:500, Cat\# sc-69879, RRID:AB_1119529; Santa Cruz Biotechnology) was considered as control. A chemiluminescence detection system reagent was used. ${ }^{24}$

\section{Cytokine production}

The proinflammatory levels of cytokines such as TNF- $\alpha$, IL-6, and IL-1 $\beta$ were assessed by Elisa kit. TNF- $\alpha$, IL-6, and IL-1 $\beta$ ELISA assays were performed according to manufacturer's details (Cat\# DY5670, DY7464, DY7984; R\&D System, United Kingdom).

\section{Intracellular ROS determination}

To better study the effect of Tempol on both oxidative stress and antioxidant capacity of Tempol on SIRC cells stimulated with LPS, we analyzed the ROS content. Intracellular ROS was revealed using the total ROS detection kit as previously displayed. ${ }^{25}$

\section{Prostaglandin E2 level}

To better examine the inflammatory response related to LPS stimulation, we also assessed the prostaglandin E2 $\left(\mathrm{PGE}_{2}\right)$ production in supernatants of cells incubated for $24 \mathrm{~h}$. $\mathrm{PGE}_{2}$ levels were designed in culture medium by a competitive binding ELISA according to the manufacturer's instructions (ab133021; Abcam, Inc., Cambridge, MA).

\section{Superoxide dismutase activity}

In the cells, superoxide dismutase (SOD) was calculated by nitro blue tetrazolium (NBT) reaction as previously suggested. $^{26}$ The reaction mixture, with $0.2 \mathrm{~mL}$ of supernatant, $2.4 \mathrm{~mL}$ of $50 \mathrm{mM} \mathrm{Na} \mathrm{CO}_{3}, 0.1 \mathrm{~mL}$ of $3 \mathrm{mM}$ EDTA, $0.1 \mathrm{~mL}$ of $3 \mathrm{mM}$ xanthine, $0.1 \mathrm{~mL}$ of $0.8 \mathrm{mM} \mathrm{NBT}$, and $0.1 \mathrm{~mL}$ of xanthine oxidase (XO), was saturated with $\mathrm{O}_{2}$ and incubated for $30 \mathrm{~min}$ at $24^{\circ} \mathrm{C}$. The inhibition of NBT reduction in each sample was calculated spectrophotometrically at $470 \mathrm{~nm}$. The SOD content, expressed as $\mathrm{mU} / \mathrm{mg}$ protein, was measured by relating to inhibition by the SOD 
standard detected at the same time. The detection limit was $0.4 \mathrm{mU}$ of total activity for assay.

\section{Materials}

All compounds were obtained from Sigma-Aldrich Company. All other reagents were of topmost money-making grade obtainable. All stock solutions were prearranged in nonpyrogenic saline $(0.9 \% \mathrm{NaCl}$; Baxter, Milan, Italy).

\section{Statistical calculation}

All values were articulated as mean \pm standard error of the mean of $\mathrm{N}$ observations. A $P$ value of $<0.05$ was deliberated significant. The outcomes were examined by one-way ANOVA, followed by a Bonferroni post hoc test for multiple assessments.

\section{Results}

\section{Tempol effect on cell viability}

The high concentration of 6 and $10 \mathrm{mM}$ is able to diminish the cell viability by $44 \%$ and $16 \%$, respectively, while the
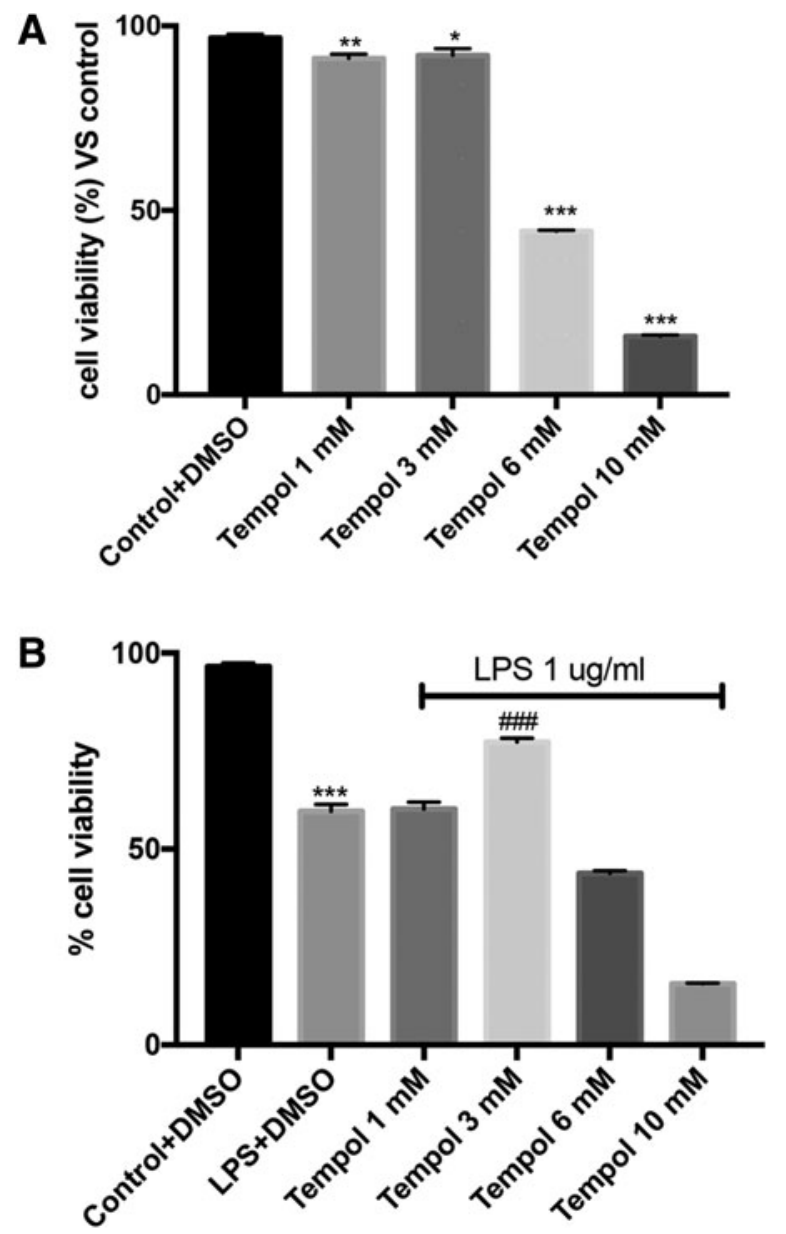

FIG. 1. Effect of Tempol on cell viability. Cell viability was assessed $24 \mathrm{~h}$ after treatment at the indicated concentrations $(1,3$, 6 , and $10 \mathrm{mM}$ ) of Tempol with and without LPS stimulation (A, B). Values are given as mean \pm SEM of $n=10$ wells for each group in duplicate. Each assay was repeated 3 times in different days. Data are representative of 3 independent experiments; $* P<$

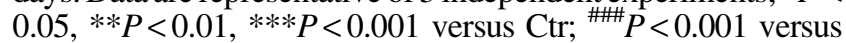
LPS. LPS, lipopolysaccharide; SEM, standard error of the mean. concentrations of 1 and $3 \mathrm{mM}$ exhibited no toxic effects on cell viability, which is $\sim 91 \%$ and $92 \%$. Moreover, in our study, the cells were stimulated with LPS to produce inflammatory response, and also pretreated with Tempol. The findings acquired reported a relevant protective effect against LPS-induced inflammatory process in cells pretreated with Tempol only at $3 \mathrm{mM}(77 \%)$, whereas pretreatment at other concentrations showed no significant protection (Fig. 1A, B). Since the concentrations of 6 and $10 \mathrm{mM}$ produced a high reduction of the cell viability, both concentrations were not employed in additional experiments. Based on this, we decided to perform all experiments with $3 \mathrm{mM}$ Tempol.

\section{Tempol effect on ROS production and SOD activity}

The untreated control group discharged low levels of ROS, while LPS stimulation considerably increased ROS content (Fig. 2A). Pretreatment with Tempol at $3 \mathrm{mM}$ significantly
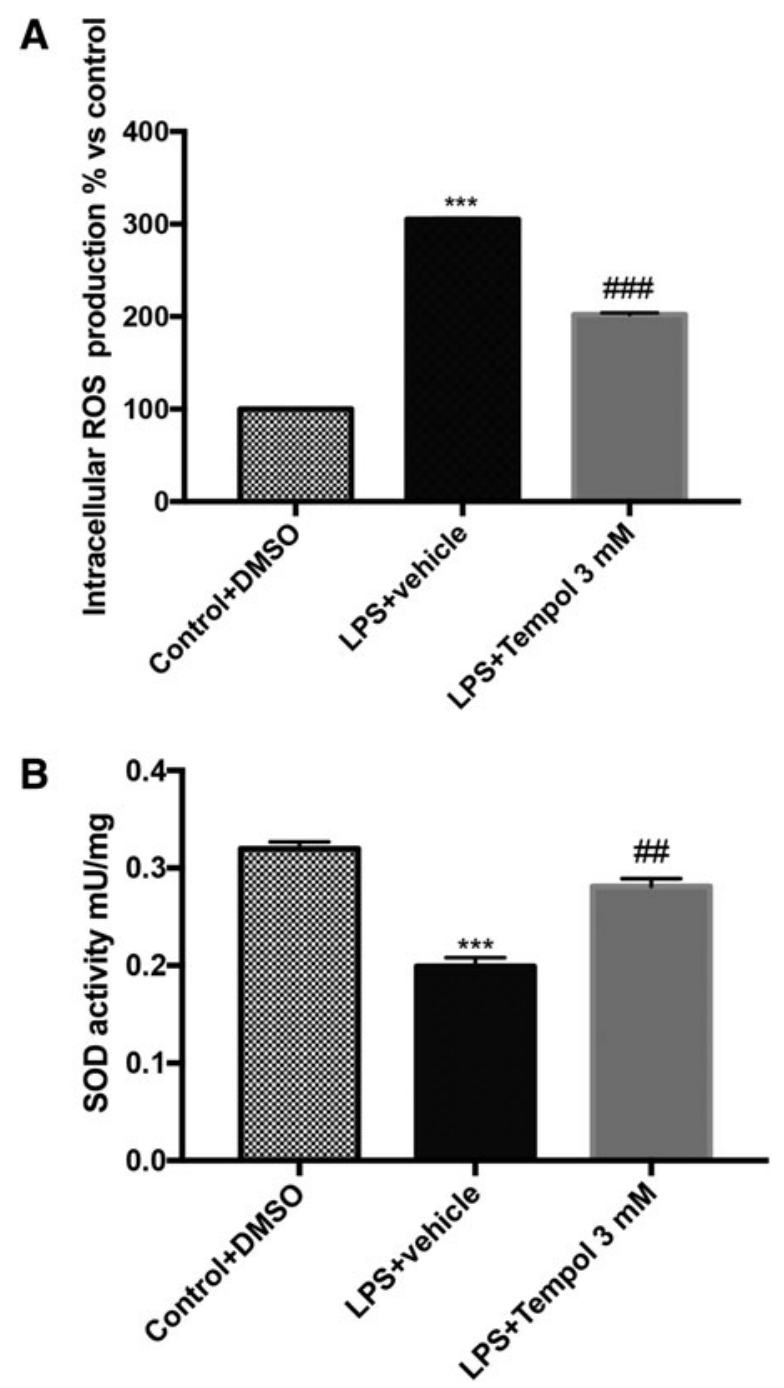

FIG. 2. Effect of Tempol on cell ROS production and SOD activity. The figure shows the levels of ROS content (A) and antioxidant SOD activity (B). Values are given as mean \pm SEM of $n=10$ wells for each group in duplicate. Each assay was repeated 3 times in different days. Data are representative of 3 independent experiments; $* * * P<0.001$

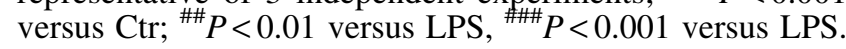
ROS, reactive oxygen species; SOD, superoxide dismutase. 
decreased ROS levels (Fig. 2A). Moreover, SOD activity was calculated. LPS stimulation diminished SOD activity in SIRC cells (Fig. 2B). The concentration of $3 \mathrm{mM}$ of Tempol is able to prevent the decrease in SOD activity (Fig. 2B).

\section{Effect of Tempol on TNF- $\alpha, I L-1 \beta$, and IL-6 levels}

A significant increase in the production of TNF- $\alpha$, IL-6, and IL-1 $\beta$ was analyzed after LPS stimulation (Fig. 3A-C). Nevertheless, pretreatment with Tempol at $3 \mathrm{mM}$ significantly reduced all cytokine levels (Fig. 3A-C).

\section{Effect of Tempol on $P G E_{2}$ levels and COX-2 expression}

Tempol in SIRC cells (deprived of LPS) had no relevant effect on $\mathrm{PGE}_{2}$ production (Fig. 4A). As estimated, LPS induced a significant growth in $\mathrm{PGE}_{2}$ production compared with control (Fig. 4A). Tempol treatment in LPS-stimulated SIRC produced a substantial reduction in $\mathrm{PGE}_{2}$ levels expression (Fig. 4A). In this regard, COX-2 expression in SIRC (Fig. 4B) after LPS stimulation was also measured. On the contrary, LPS-stimulated SIRC significantly expressed inducible COX-2 matched to control (without LPS) (Fig. 4B). Tempol treatment $(3 \mathrm{mM})$ significantly diminished the LPS-SIRC COX-2 expression (Fig. 4B).

\section{Discussion}

Corneal inflammation causes a substantial harm to vision with scraping and hole produced by bacterial keratitis or pathogen products, for example LPS. ${ }^{27}$ LPS, the main element of the cell barrier of gram-negative bacteria, is a fundamental feature in generating abundant cytokines and triggering inflammatory response in many tissues, such as cornea. ${ }^{2}$ During the inflammation associated with infectious keratitis, PMN aggregation takes place in the cornea. The activation of PMN causes a "respiratory burst" that together with the activation of arachidonic acid cascade results in considerable release of different free radicals in the inflamed cornea, which act as potent oxidizing agents causing protein alteration, DNA degeneration, and lipid peroxidation of the cell membrane. Antioxidant substances have been investigated in diverse models of experimental keratitis demonstrating a protective response. ${ }^{5}$ The role nowadays recognized to oxidative stress in the advance of inflammatory disorders underlines the importance of antioxidant therapy in optimizing the use of treatments for these pathologies.

Among numerous antioxidants offered, Tempol is a membrane-permeable, catalytic, metal-independent antioxidant. It is an interesting compound because it activates the metabolism of O2- similar to the activity of SOD, and is considered in fact a mimetic of SOD. However, Tempol abolishes the metabolism of reactive oxygen and nitrogen species, and increases the antioxidant action of the catalase.
FIG. 3. Effect of Tempol on cytokines levels. The figure shows the cytokine levels of TNF- $\alpha(\mathbf{A})$, IL-1 $\beta$ (B), and IL-6 (C). Values are given as mean \pm SEM of $n=10$ wells for each group in duplicate. Each assay was repeated 3 times in different days. Data are representative of 3 independent experiments; $* * * P<0.001$ versus Ctr; ${ }^{\# \# \# ~} P<0.001$ versus LPS. IL, interleukin; ND, not detectable; TNF, tumor necrosis factor.
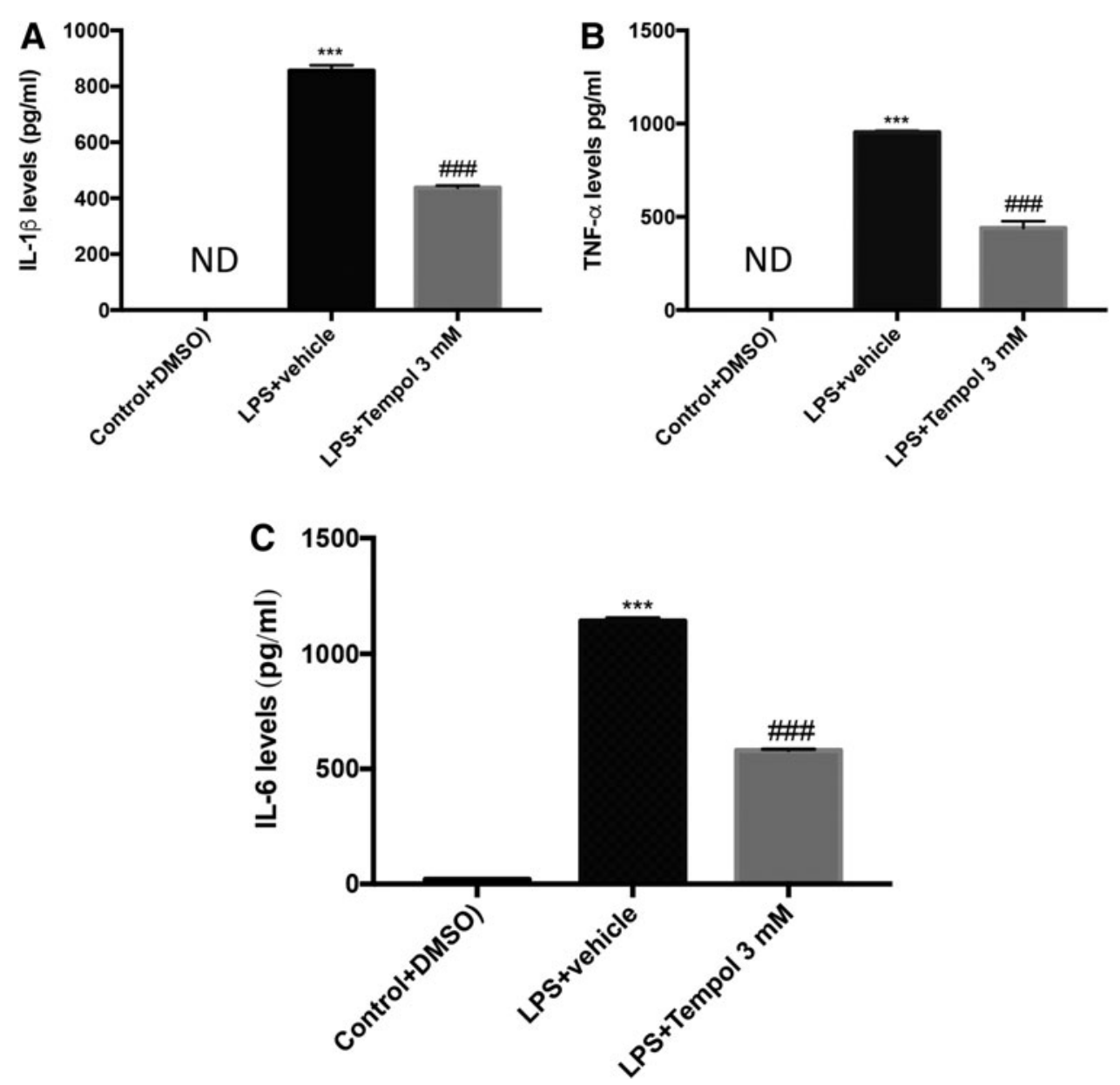
A

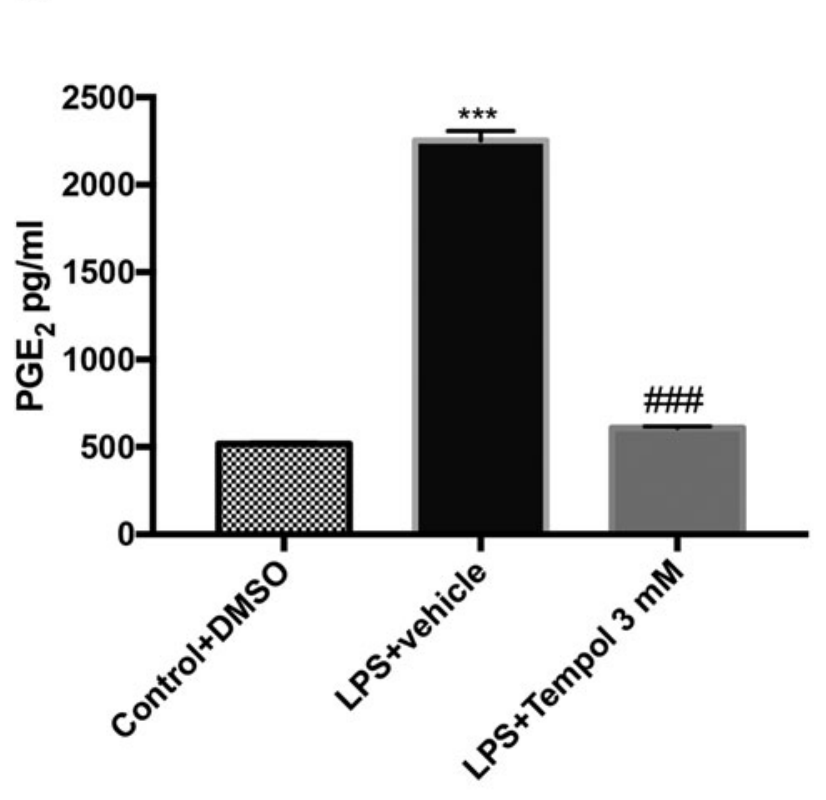

B
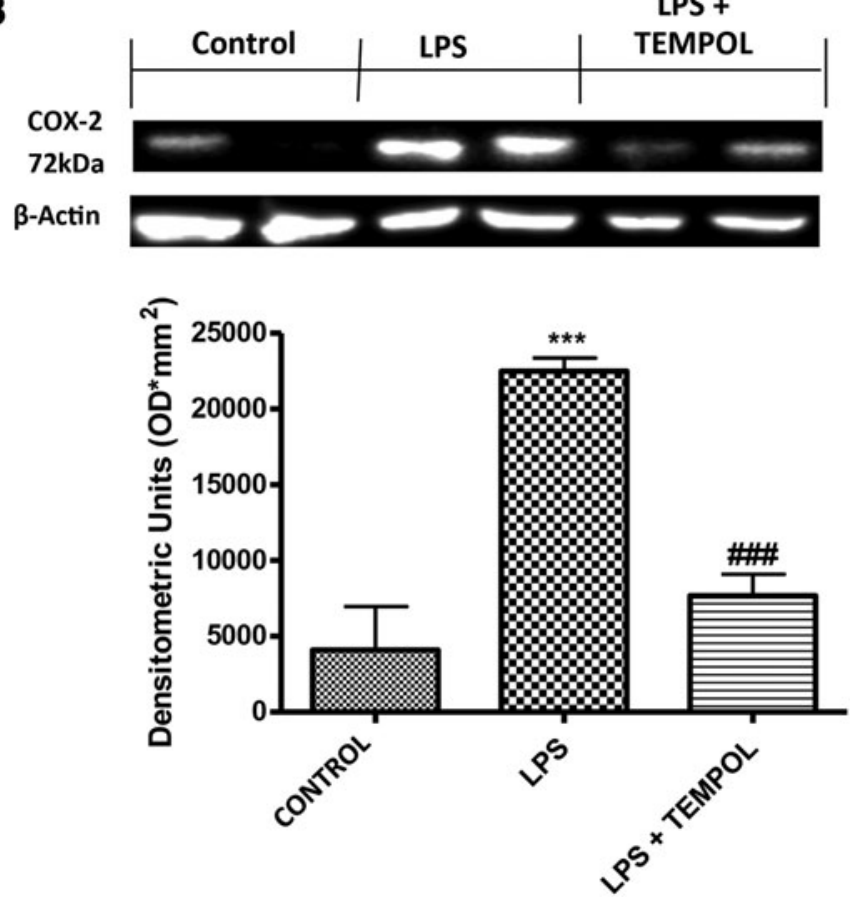

FIG. 4. Effect of Tempol on $\mathrm{PGE}_{2}$ levels and COX-2 expression. The figure shows $\mathrm{PGE}_{2}$ levels (A) and COX-2 expression (B). A representative blot is shown $(\mathbf{B})$. Densitometric analysis of protein expression of 3 gel pictures obtained in 3 different experiments, normalized to $\beta$-actin $(\mathbf{B}) * * * P<0.001$ versus $\mathrm{Ctr}$; \#\# $P<0.001$ versus LPS. COX-2, cyclooxygenase-2; $\mathrm{PGE}_{2}$, prostaglandin $\mathrm{E} 2$.

Tempol is able to increase the bioavailability of NO and catalytically removes the peroxynitrite species (ONOO-), and has been studied in many models of oxidative stress. ${ }^{28,29}$ Thus, radical-induced oxidative stress and inflammation can be modulated by Tempol (TP)-based nitroxide drugs to prevent or treat vascular, ocular, and other pathological conditions and aging-associated disease. ${ }^{30}$

For these reasons, the aim of our research was to study the effects of Tempol on in vitro model of eye inflammation in SIRC cells. In this study, SIRC cell line was used because it presents a morphology that is more coherent with a fibroblastic cell phenotype, comparable with corneal keratocytes. $^{22}$ Here, we confirmed that Tempol was able to respond to the inflammatory process and oxidative stress caused by LPS in rabbit corneal cells. Moreover, LPSstimulated SIRC cells showed improved ROS production and diminished cell viability and antioxidant SOD activity. Treatment with Tempol significantly diminished intracellular ROS levels as well as enhanced both cell viability and antioxidant activity. These results are in accord with previous in vitro study in which Tempol attenuated PC12 cells damage encouraged by hypoxia with increased cell viability, inhibited oxidative stress, and normalized SOD activity. ${ }^{31}$ The protective effect of Tempol derivatives against retinal damage induced by light has previously been observed in rats. 16

Therefore, Tempol had a significant influence on the cellular skeleton of retinal ganglion cells in methanolpoisoned rats. ${ }^{32}$ The enrollment of lymphocytes at sites of inflammation is caused by the action of proinflammatory cytokines IL-1 $\beta$ or TNF- $\alpha$. Prostaglandins (PGs) have a major contribution to intraocular damage. Several studies in dogs have reported the quantification of $\mathrm{PGE}_{2}$ levels as a measure of intraocular inflammation. ${ }^{33}$ Furthermore, a significant increase in gene expression of COX-2, IL- $\beta$, and IL8 has been found in an experimental model of uveitis and in human ARPE-19 cells activated by LPS. ${ }^{34}$ A previous study on keratitis also showed an increase in the expression of COX-2 in the canine cornea. ${ }^{35}$ Furthermore, mice subdued to hostile conditions showed elevated levels of COX-2, PGE synthase mRNA levels on the ocular surface. ${ }^{34}$ In this regard, in our research, SIRC excited by LPS have significantly increased levels of TNF- $\alpha$, IL-1, and IL-6, expression of COX-2, and excessive levels of $\mathrm{PGE}_{2}$. The administration of Tempol significantly reduced the induction of COX-2 production. Furthermore, the treatment with Tempol in SIRC activated by LPS has elicited a critical decrease in both the cytokines and the $\mathrm{PGE}_{2}$ levels. Our data are also in agreement with other reports in which Tempol was successful in causing lens epithelial DNA injury and cataract development in X-ray subjected rabbits ${ }^{15}$ as well as was able to reduce proinflammatory cytokines, including IL-1 and $\mathrm{TNF}-\alpha$, in ocular hypertensive eyes. ${ }^{17}$

In summary, in our study we described that Tempol was able to reduce eye inflammation in in vitro model of SIRC cells stimulated with LPS. This research exhibited that Tempol was able to reduce oxidative stress, proinflammatory cytokine levels such as TNF, IL-1, and IL-6, and COX-2 protein that has significant roles in the keratitis disorder, and could exemplify a new therapeutic strategy for management of ocular inflammatory disorders in both humans and animals.

\section{Acknowledgment}

The authors thank Miss Malvagni Valentina for her editorial assistance with the article. 


\section{Authors' Contributions}

RC and DI made contribution to conception and design, acquisition of data, interpretation of data, and drafting of the article; EG, MC, and RS were involved in acquisition of data and analysis; DB, SC, and RDP revised critically the article. All authors have read and approved the final article.

\section{Author Disclosure Statement}

No competing financial interests exist.

\section{Funding Information}

No funding was received for this article.

\section{References}

1. Zhu, S., Xu, X., Wang, L., Su, L., Gu, Q., Wei, F., and Liu, K. Inhibitory effect of a novel peptide, $\mathrm{H}-\mathrm{RN}$, on keratitis induced by LPS or poly(I:C) in vitro and in vivo via suppressing NFkappaB and MAPK activation. J. Transl. Med. 15:20, 2017.

2. Chen, G., Zhang, J., Zhang, H., Xiao, Y., Kao, X., Liu, Y., and Liu, Z. Anti-inflammatory effect of emodin on lipopolysaccharide-induced keratitis in Wistar rats. Int. J. Clin. Exp. Med. 8:12382-12389, 2015.

3. Marquart, M.E. Animal models of bacterial keratitis. $J$. Biomed. Biotechnol. 2011:680642, 2011.

4. Yan, H., Wang, Y., Shen, S., Wu, Z., and Wan, P. Corticosteroids effects on LPS-induced rat inflammatory keratocyte cell model. PLoS One. 12:e0176639, 2017.

5. Alio, J.L., Artola, A., Serra, A., Ayala, M.J., and Mulet, M.E. Effect of topical antioxidant therapy on experimental infectious keratitis. Cornea. 14:175-179, 1995.

6. Alio, J.L., Ayala, M.J., Mulet, M.E., Artola, A., Ruiz, J.M., and Bellot, J. Antioxidant therapy in the treatment of experimental acute corneal inflammation. Ophthalmic. Res. 27:136-143, 1995.

7. Ruban, V.V., Archana, P.T., Sundararajan, M., Geraldine, P., and Thomas, P.A. Inflammation and oxidative stress in corneal tissue in experimental keratitis due to Fusarium solani: amelioration following topical therapy with voriconazole and epigallocatechin gallate. Mycoses. 61:159-171, 2018.

8. Bucolo, C., Fidilio, A., Platania, C.B.M., Geraci, F., Lazzara, F., and Drago, F. Antioxidant and osmoprotecting activity of taurine in dry eye models. J. Ocul. Pharmacol. Ther. 34:188-194, 2018.

9. Ciuffi, M., Pisanello, M., Pagliai, G., Raimondi, L., Franchi-Micheli, S., Cantore, M., Mazzetti, L., and Failli, P. Antioxidant protection in cultured corneal cells and whole corneas submitted to UV-B exposure. J. Photochem. Photobiol B. 71:59-68, 2003.

10. Cuzzocrea, S., McDonald, M.C., Mazzon, E., Filipe, H.M., Centorrino, T., Lepore, V., Terranova, M.L., Ciccolo, A., Caputi, A.P., and Thiemermann, C. Beneficial effects of tempol, a membrane-permeable radical scavenger, on the multiple organ failure induced by zymosan in the rat. Crit. Care Med. 29:102-111, 2001.

11. Chatterjee, P.K., Cuzzocrea, S., Brown, P.A., Zacharowski, K., Stewart, K.N., Mota-Filipe, H., and Thiemermann, C. Tempol, a membrane-permeable radical scavenger, reduces oxidant stress-mediated renal dysfunction and injury in the rat. Kidney Int. 58:658-673, 2000.

12. Cuzzocrea, S., McDonald, M.C., Filipe, H.M., Costantino, G., Mazzon, E., Santagati, S., Caputi, A.P., and Thie- mermann, C. Effects of tempol, a membrane-permeable radical scavenger, in a rodent model of carrageenaninduced pleurisy. Eur. J. Pharmacol. 390:209-222, 2000.

13. Cuzzocrea, S., McDonald, M.C., Mazzon, E., Siriwardena, D., Costantino, G., Fulia, F., Cucinotta, G., Gitto, E., Cordaro, S., Barberi, I., De Sarro, A., Caputi, A.P., and Thiemermann, C. Effects of tempol, a membranepermeable radical scavenger, in a gerbil model of brain injury. Brain Res. 875:96-106, 2000.

14. Cuzzocrea, S., McDonald, M.C., Mazzon, E., Dugo, L., Lepore, V., Fonti, M.T., Ciccolo, A., Terranova, M.L., Caputi, A.P., and Thiemermann, C. Tempol, a membrane-permeable radical scavenger, reduces dinitrobenzene sulfonic acidinduced colitis. Eur. J. Pharmacol. 406:127-137, 2000.

15. Sasaki, H., Lin, L.R., Yokoyama, T., Sevilla, M.D., Reddy, V.N., and Giblin, F.J. TEMPOL protects against lens DNA strand breaks and cataract in the x-rayed rabbit. Invest. Ophthalmol. Vis. Sci. 39:544-552, 1998.

16. Tanito, M., Li, F., Elliott, M.H., Dittmar, M., and Anderson, R.E. Protective effect of TEMPOL derivatives against light-induced retinal damage in rats. Invest. Ophthalmol. Vis. Sci. 48:1900-1905, 2007.

17. Yang, X., Hondur, G., and Tezel, G. Antioxidant treatment limits neuroinflammation in experimental glaucoma. Invest. Ophthalmol. Vis. Sci. 57:2344-2354, 2016.

18. Jing, L., Li, Q., He, L., Sun, W., Jia, Z., and Ma, H. Protective effect of tempol against hypoxia-induced oxidative stress and apoptosis in H9c2 cells. Med. Sci. Monit. Basic Res. 23:159-165, 2017.

19. Bruschetta, G., Impellizzeri, D., Morabito, R., Marino, A., Ahmad, A., Spano, N., Spada, G.L., Cuzzocrea, S., and Esposito, E. Pelagia noctiluca (Scyphozoa) crude venom injection elicits oxidative stress and inflammatory response in rats. Mar. Drugs. 12:2182-2204, 2014.

20. Petrovski, G., Pasztor, K., Orosz, L., Albert, R., Mencel, E., Moe, M.C., Kaarniranta, K., Facsko, A., and Megyeri, K. Herpes simplex virus types 1 and 2 modulate autophagy in SIRC corneal cells. J. Biosci. 39:683-692, 2014.

21. Niederkorn, J.Y., Meyer, D.R., Ubelaker, J.E., and Martin, J.H. Ultrastructural and immunohistological characterization of the SIRC corneal cell line. In Vitro Cell. Dev. Biol. 26:923-930, 1990.

22. Olivieri, M., Cristaldi, M., Pezzino, S., Rusciano, D., Tomasello, B., Anfuso, C.D., and Lupo, G. Phenotypic characterization of the SIRC (Statens Seruminstitut Rabbit Cornea) cell line reveals a mixed epithelial and fibroblastic nature. Exp. Eye Res. 172:123-127, 2018.

23. Coutinho, A.B., Freitas, D., Souza Filho, J.P., Correa, Z.M., Odashiro, A.N., and Burnier, M.N., Jr. Cytokeratin expression in corneal dystrophies. Arq. Bras. Oftalmol. 74: 118-122, 2011.

24. Paterniti, I., Impellizzeri, D., Cordaro, M., Siracusa, R., Bisignano, C., Gugliandolo, E., Carughi, A., Esposito, E., Mandalari, G., and Cuzzocrea, S. The anti-inflammatory and antioxidant potential of Pistachios (Pistacia vera L.) in vitro and in vivo. Nutrients. 9, 2017. pii: E915.

25. Perez, A.P., Casasco, A., Schilrreff, P., Tesoriero, M.V., Duempelmann, L., Pappalardo, J.S., Altube, M.J., Higa, L., Morilla, M.J., Petray, P., and Romero, E.L. Enhanced photodynamic leishmanicidal activity of hydrophobic zinc phthalocyanine within archaeolipids containing liposomes. Int. J. Nanomed. 9:3335-3345, 2014.

26. Lodovici, M., Raimondi, L., Guglielmi, F., Gemignani, S., and Dolara, P. Protection against ultraviolet B-induced oxidative DNA damage in rabbit corneal-derived cells 
(SIRC) by 4-coumaric acid. Toxicology. 184:141-147, 2003.

27. Carlson, E.C., Drazba, J., Yang, X., and Perez, V.L. Visualization and characterization of inflammatory cell recruitment and migration through the corneal stroma in endotoxin-induced keratitis. Invest. Ophthalmol. Vis. Sci. 47:241-248, 2006.

28. Wilcox, C.S. Effects of tempol and redox-cycling nitroxides in models of oxidative stress. Pharmacol. Ther. 126: 119-145, 2010.

29. Batinic-Haberle, I., Reboucas, J.S., and Spasojevic, I. Superoxide dismutase mimics: chemistry, pharmacology, and therapeutic potential. Antioxid. Redox Signal. 13:877-918, 2010.

30. Zarling, J.A., Brunt, V.E., Vallerga, A.K., Li, W., Tao, A., Zarling, D.A., and Minson, C.T. Nitroxide pharmaceutical development for age-related degeneration and disease. Front. Genet. 6:325, 2015.

31. Ma, H., Wang, X., Qi, X., Jing, L., Sun, W., and Jia, Z. Tempol protect against hypoxia induced oxidative stress in PC12 cells. Int. J. Clin. Exp. Med. 10:6071-6080, 2017.

32. Setiohadji, B., Irfani, I., Rifada, M., Virgana, R., and Kartasasmita, A.S. The superoxide dismutase mimetic TEMPOL and its effect on retinal ganglion cells in experimental methanol-intoxicated rats. Ophthalmol. Ther. 7: 167-172, 2018.
33. Ortencio, K.P., Renzo, R., Sobrinho, B.A., Kobashigawa, K.K., Crivelaro, R.M., Silva, G.A., Aldrovani, M., Ribeiro, A.P., Mineo, T.W., and Laus, J.L. Effects of morphine on the expression of cytokines and inflammatory mediators in a rabbit model of endotoxin-induced experimental uveitis. Arq. Bras. Oftalmol. 78:371-375, 2015.

34. Anfuso, C.D., Olivieri, M., Fidilio, A., Lupo, G., Rusciano, D., Pezzino, S., Gagliano, C., Drago, F., and Bucolo, C. Gabapentin attenuates ocular inflammation: in vitro and in vivo studies. Front. Pharmacol. 8:173, 2017.

35. Sellers, R.S., Silverman, L., and Khan, K.N. Cyclooxygenase2 expression in the cornea of dogs with keratitis. Vet. Pathol. 41:116-121, 2004.

Received: March 8, 2019 Accepted: September 11, 2019

Address correspondence to:

Prof. Salvatore Cuzzocrea

Department of Chemical, Biological, Pharmaceutical and Environmental Sciences University of Messina Viale Ferdinando Stagno D’Alcontres $n^{\circ} 31$ Messina 98166 Italy

E-mail: salvator@unime.it 